\title{
Review: Outcomes of Revascularization Strategies for Coronary Artery Disease
}

\author{
Turki B. Albacker*, Hanan Albackr, Mostafa Al Shamiri, Abdulelah F. Al Mobeirek \\ King Fahad Cardiac Center, College of Medicine, King Saud University, Riyadh, KSA \\ Email: "talbacker@ksu.edu.sa
}

Received 12 February 2014; revised 2 March 2014; accepted 20 March 2014

Copyright $@ 2014$ by authors and Scientific Research Publishing Inc.

This work is licensed under the Creative Commons Attribution International License (CC BY). http://creativecommons.org/licenses/by/4.0/

(c) (i) Open Access

\section{Abstract}

The optimal revascularization strategy for patients with coronary artery disease is influenced by the continuous improvement in medical therapy and the improved designs of the new generation of coronary stents allowing them to be increasingly applied in patients with complex coronary anatomy, including those with left main stem disease. On the other hand, surgical results are also improved as a result of the increased experience over years and the improvement of myocardial protection techniques. This will make the comparison of percutaneous coronary interventions and coronary artery bypass surgery a moving target. In this paper, we reviewed the recent randomized controlled trials and important registries emphasizing the benefits and the results of each therapy in different patient subsets. A heart team of both cardiologists and cardiac surgeons is of paramount importance in choosing the optimal revascularization strategy.

\section{Keywords}

Outcomes; Revascularization; Coronary Artery Bypass Grafting; Percutaneous Coronary Intervention; Survival; Major Adverse Cardiovascular; Cerebrovascular Events

\section{Introduction}

The optimal revascularization strategy for patients with coronary artery disease (CAD) is influenced by the continuous improvement in medical therapy including the use of dual antiplatelet therapy and lipid lowering agents. The improved designs of the new generation of coronary stents along with using drug eluting stents (DES) have decreased the rate of early stent thrombosis or restenosis allowing them to be increasingly applied in patients with complex coronary anatomy, including those with left main (LM) stem stenosis or with multivessel disease (MVD). Percutaneous coronary intervention (PCI) for unprotected left main (LM) with limited additional dis-

*Corresponding author.

How to cite this paper: Albacker, T.B., Albackr, H., Al Shamiri, M. and Al Mobeirek, A.F. (2014) Review: Outcomes of Revascularization Strategies for Coronary Artery Disease. International Journal of Clinical Medicine, 5, 260-274. 
ease has been revised to a class II recommendation in the recent US and European guidelines. Additionally, PCI may reduce mortality in acute coronary syndromes (ACS) [1] and ameliorate ischemia [2] [3]. However, it appears to offer no advantage regarding survival or myocardial infarction (MI) over optimal medical treatment (OMT) in stable, low-risk patients [4]. On the other hand, surgical results are also improved as a result of the increased experience over years and the improvement of myocardial protection techniques. Theoretically, coronary artery bypass grafting (CABG) may ensure better myocardial protection than PCI by bypassing both existing and future culprit lesions as compared with stenting the culprit coronary stenos alone. CABG confers a mortality reduction over OMT in high-risk patients with both LM or MVD and left ventricular (LV) systolic dysfunction. Emerging evidence suggests that patients with higher atheroma burden, as indicated by older age, presence of diabetes mellitus (DM) and extensive MVD in combination with LV dysfunction may derive the greatest benefit from CABG. Whether PCI might be preferred as an initial strategy in stable patients with MVD and/or LM, disease remains debatable.

\section{Individual Data}

\subsection{Clinical Trials}

\subsubsection{SYNTAX (Synergy between PCI with Taxus and Cardiac Surgery)}

The SYNTAX trial [5] is an 85-centre randomized clinical trial that prospectively screened, consecutive left main $(\mathrm{LM})$ and/or triple vessel disease (TVD) patients $(\mathrm{n}=1800)$ and randomized them if amenable to equivalent revascularization using either CABG or PCI with DES. The one year follow up results showed that rates of major adverse cardiac or cerebrovascular events were significantly higher in the PCI group (17.8\% vs. $12.4 \%$ for CABG, $\mathrm{p}=0.002)$, in large part because of an increased rate of repeat revascularization $(13.5 \%$ vs. $5.9 \%, \mathrm{p}<$ 0.001). The rates of death and myocardial infarction were similar between the two groups; stroke was significantly higher with CABG $(2.2 \%$ vs. $0.6 \%$ with PCI, $\mathrm{p}=0.003)$.

In a subgroup analysis of the SYNTAX trial for diabetic patients [6], revascularization with DES resulted in higher 1 year repeat revascularization for non-diabetic patients $(5.7 \%$ vs. $11.1 \%, \mathrm{p}=0.001)$ and diabetic patients (6.4\% vs. $20.3 \%, p=0.001)$ and consequently higher major adverse cardiac and cerebrovascular event (MACCE) rate. However, the revascularization method did not impact the death/stroke/myocardial infarction rate for non-diabetic patients $(6.8 \%$ CABG vs. $6.8 \%$ DES, $\mathrm{p}=0.97)$ or for diabetic patients $(10.3 \%$ CABG vs. $10.1 \%$ DES, $\mathrm{p}=0.96$ ). The only group that showed higher mortality after DES compared to CABG was patients with highly complex lesions whether they were diabetic $(4.1 \%$ CABG vs. $13.5 \%$ DES, $p=0.04)$ or non-diabetic (2.2\% CABG vs. $6.1 \%$ DES, $p=0.04)$.

At 3 years [7], MACCE [death, stroke, myocardial infarction (MI), and repeat revascularization] were elevated in the PCI arm (CABG $20.2 \%$ vs. PCI $28.0 \%$, p, 0.001), as well as repeat revascularization (10.7\% vs. $19.7 \%, \mathrm{p}, 0.001)$, and $\mathrm{MI}(3.6 \%$ vs. $7.1 \%, \mathrm{p} 1 / 4,0.002)$. Rates of the composite safety endpoint (death/stroke/MI) and stroke alone were not significantly different between treatment groups. MACCE rates were not significantly different between arms in the LM subgroup $(22.3 \%$ vs. $26.8 \%, \mathrm{p}=0.20)$ but were higher with PCI in the 3VD subgroup $(18.8 \%$ vs. $28.8 \%, p=0.001)$ and diabetic patients $(22.9 \%$ vs. $37 \%, p=0.002)$. Overall mortality $(9.5 \%$ vs. $5.7 \%, \mathrm{p}=0.02)$ and cardiac death were significantly increased in 3VD patients treated with PCI $(6.2 \%$ vs. $2.9 \%, \mathrm{p}=0.01)$. In the LM cohort, there was no difference in all-cause or cardiac death rates in CABG- or PCI-treated patients (all-cause: CABG $8.4 \%$ vs. PCI 7.3\%, $\mathrm{p}=0.64$; cardiac death $4.6 \%$ vs. $5.7 \%$, p = 0.48).

SYNTAX trial is the first study that looked at the relationship between lesion complexity and the outcome. Patients with 3VD with SYNTAX scores in the lowest tercile exhibited similar MACCE rates between treatment arms (CABG 22.2\% vs. PCI 25.8\%, $\mathrm{p}=0.45$ ). In those 3VD patients with intermediate or high SYNTAX scores, the rate of MACCE was significantly increased in favor of CABG (23 - 32: CABG $16.8 \%$ vs. PCI $29.4 \%, \mathrm{p}=$ $0.003 ; \geq 33$ : CABG $17.9 \%$ vs. PCI $31.4 \%, \mathrm{p}=0.004)$. Myocardial infarction was significantly higher in the PCI arm of the 3VD intermediate SYNTAX score tercile (3.1 vs. 8.9\%, $\mathrm{p}=0.01)$. In 3VD patients with SYNTAX score $\geq 33$, mortality (CABG $4.5 \%$ vs. PCI $11.1 \%, \mathrm{p}=0.03)$ and $\mathrm{MI}(1.9 \%$ vs. $7.2 \%$, $\mathrm{p}=0.02)$ were significantly higher in the PCI arm. MACCE rates were not significantly different in patients with LM disease who had low or intermediate SYNTAX scores (0 - 22: CABG 23.0\% vs. PCI 18.0\%, p = 0.33; 23 - 32: CABG 23.4\% vs. PCI $23.4 \%, p=0.90$ ). In LM patients with the most complex anatomy (SYNTAX score $\geq 33$ ), MACCE was significantly increased in PCI-treated patients (CABG $21.2 \%$ vs. PCI $37.3 \%, \mathrm{p}=0.003$ ) as was repeat revascularization $(9.2 \%$ vs. $27.7 \%, \mathrm{p}=0.001)$. It is of note that the distribution of LM patients with concurrent $3 \mathrm{VD}$ was 
greatest in the "high" SYNTAX score group in the overall patient population. Additionally, an increased proportion of distal LM lesions were found in the patients with "high" SYNTAX scores compared with patients in the low and intermediate terciles.

\subsubsection{BARI (Bypass Angioplasty Revascularization Investigation)}

This trial [8] was conducted from 1989 to 1991 and enrolled 1829 patients, which represented a small proportion (only 7.3\%) of patients who were screened. Symptomatic patients with MVD were randomized to an initial strategy of PTCA or CABG. Stents and IIb/IIIa inhibitors were not utilized. In the subgroup with treated diabetes, the CABG assigned group had higher survival than the PCI assigned group (PCI $45.5 \%$ vs. CABG $57.8 \%, \mathrm{p}=0.025$ ). Seven-year survival among patients with three-vessel disease undergoing PCI and CABG (n $=754)$ was $79 \%$ versus $84 \%(p=0.06)$, respectively, and $85 \%$ versus $87 \%(p=0.36)$ when only non-diabetics $(\mathrm{n}=592)$ were analyzed. In patients with three-vessel disease and reduced LV function (ejection fraction < $50 \%)$, seven-year survival was 70\% versus $74 \%(\mathrm{p}=0.6)$ in all PCI and CABG patients $(\mathrm{n}=176)$, and $82 \%$ versus $73 \%(p=0.29)$ among non-diabetic patients $(n=124)$. Seven-year survival was $87 \%$ versus $84 \%(p=0.9)$ in all PCI and CABG patients (including diabetics) with two-vessel disease involving the proximal LAD ( $\mathrm{n}=$ $352)$, and $78 \%$ versus $71 \%(\mathrm{p}=0.7)$ in patients with two-vessel disease involving the proximal LAD with reduced LV function ( $\mathrm{n}=72$ ). If only non-diabetic patients with two-vessel disease including the proximal LAD are analyzed $(n=287)$, seven-year survival was better in the PCI patients compared with the CABG patients (93\% vs. $86 \%, p=0.27)$, although the difference was not statistically significant. Seven-year survival among non-diabetic patients with two-vessel disease including the proximal LAD and reduced ventricular function tended to be greater among patients treated with PCI $(90 \%$ vs. $67 \%$, p $=0.13)$, although only 46 such patients were enrolled in BARI.

The 10-year results of the BARI [9] showed that there was no significant long-term disadvantage regarding mortality or myocardial infarction associated with an initial strategy of PCI compared with CABG. Among patients with treated diabetes, CABG conferred long term survival benefit, whereas the 2 initial strategies were equivalent regarding survival for patients without diabetes. Survival was $71.0 \%$ for PCI and $73.5 \%$ for CABG (p $=0.18$ ). At 10 years, the PCI group had substantially higher subsequent revascularization rates than the CABG group (76.8\% vs. $20.3 \%, \mathrm{p}=0.001)$, but angina rates for the 2 groups were similar. In the subgroup of patients with no treated diabetes, survival rates were nearly identical by randomization (PCI 77.0\% vs. CABG 77.3\%, $\mathrm{p}$ $=0.59$ ). In the subgroup with treated diabetes, the CABG assigned group had higher survival than the PCI assigned group (PCI $45.5 \%$ vs. CABG $57.8 \%, \mathrm{p}=0.025$ ).

\subsubsection{EAST (Emery Angioplasty Surgery Trial)}

This trial included 450 patients. This represented only $7.7 \%$ of the patients screened for trial inclusion [10]. The eight-year mortality in the CABG group was $17.3 \%$ versus $27.7 \%$ for PCI with a relative risk reduction of $22 \%$. However, this was not statistically significant because of the relatively small number of patients included in this study. Furthermore, this trial was conducted in the era of balloon angioplasty and saphenous vein grafting, before the advent of stents and arterial conduits, both of which are proven advances in their respective therapies.

\subsubsection{SOS (Stent or Surgery)}

The trial [11] recruited patients from 53 centers in the USA and Canada concluded that the use of coronary stents reduced the need for a repeat revascularization compared with previous studies such as BARI that used balloon angioplasty, although the rate remained significantly higher than in patients managed with CABG. During the three-year follow-up period, this trial reported a greater need for repeat revascularization in the stent group (21\%) than in the CABG group (6\%) and a survival advantage in the CABG group (hazard ratio, 2.91; $95 \%$ CI, 1.29 - 6.53; $p=0.01$ ). Additionally, angina and the use of anti-anginal medications were less common in the CABG group at one-year follow-up.

\subsubsection{ARTS (Arterial Revascularization Therapy Study)}

This trial [12] randomly assigned1205 patients with MVD to BMS $(n=600)$ or CABG $(n=605)$. The primary clinical end point was freedom from MACCE at one year; MACCE at five-year follow-up constituted the final secondary end point. This study demonstrated a nearly $20 \%$ absolute reduction in the need for late revascularization in the stented patients compared with earlier PCI studies. Overall, one-year mortality was not different 
between PCI using one or more bare-metal stents and CABG. However, over the subsequent two years, $16.8 \%$ of the stent group versus $3.5 \%$ of the CABG group required further revascularization. Furthermore, complete revascularization was achieved in $84.1 \%$ of patients assigned to surgery and $70.5 \%$ of those assigned to PCI. Incomplete revascularization was associated with a five-fold increase in surgical revascularization at 1 year in the PCI patients, but not in those initially treated with CABG. Among 208 [13] diabetic patients, mortality was $13.4 \%$ in the stent group and $8.3 \%$ in the CABG group ( $p=0.27$; R, 1.61; 95\% CI, 0.71 to 3.63). Overall freedom from death, stroke, or myocardial infarction was not significantly different between groups (18.2\% in the stent group vs. $14.9 \%$ in the surgical group; $\mathrm{p}=0.14$; RR, 1.22; 95\% CI, 0.95 to 1.58). The incidence of repeat revascularization was significantly higher in the stent group (30.3\%) than in the CABG group (8.8\%; $\mathrm{p}=$ 0.001; RR, 3.46; 95\% CI, 2.61 to 4.60). The composite event-free survival rate was 58.3\% in the stent group and $78.2 \%$ in the CABG group ( $\mathrm{p}=0.0001$; RR, 1.91; 95\% CI, 1.60 to 2.28).

Diabetes mellitus was present in 112 patients in the ARTS-I BMS arm and in 96 patients in the ARTS-I CABG arm. Between February 2003 and November 2003, 607 patients, of whom 159 were diabetic, were treated with DES at 45 participating centers in the ARTS-II trial [14]. At 3 years, among non-diabetic patients, the incidence of the primary composite of death, CVA, MI, and repeat revascularization (MACCE), was significantly lower in ARTS-II than in ARTS-I PCI (adjusted odds ratio [OR]: 0.41; 95\% confidence interval [CI]: 0.26 to 0.64 ) and similar to ARTS-I CABG. The ARTS-II patients were at significantly lower risk for death, CVA, and MI as compared with both the ARTS-I PCI (adjusted OR: 0.55; 95\% CI: 0.34 to 0.91) and ARTS-I CABG patients (adjusted OR: 0.56; 95\% CI: 0.35 to 0.92). Among diabetic patients, the incidence of MACCE in ARTS-II was similar to that of both PCI and CABG in ARTS-I. Conversely, the incidence of death, CVA, and MI was significantly lower in ARTS-II than in ARTS-I PCI (adjusted OR: 0.67; 95\% CI: 0.27 to 1.65) and was similar to that of ARTS-I CABG. As expected, the MACCE rate was higher among diabetic patients receiving insulin therapy than among patients not receiving insulin treatment. There was $23.6 \%$ difference in MACCE rates between the insulin-treated and noninsulin-treated diabetic patients in the CABG arm. However, there were only 16 insulin-treated diabetic patients in the ARTS-II CABG arm, a number that precludes any definitive statement about a difference in the relative treatment effect among insulin-treated diabetic patients. After adjustment for independent predictors, diabetes proved to be the strongest pre-procedural predictor of MACCE in the ARTS-II trial (OR: 1.76; 95\% CI: 1.13 to 2.74, p = 0.012). Remarkably, the incidence of stent thrombosis (definite, probable, or possible) at 3 years was similar for the ARTS-II diabetic and non diabetic patients (6.9\% [11 of 159] vs. 6.3\% [28 of 448], respectively; $p=0.85)$.

\subsubsection{CARDia (Coronary Artery Revascularization in Diabetes)}

This trial [15] randomized 510 diabetic patients with multivessel or complex single-vessel coronary disease from 24 centers to PCI plus stenting (and routine abciximab) or CABG.

Bare-metal stents were used initially, but a switch to DES was made when these became available. At 1 year of follow-up, the composite rate of death, MI, and stroke was not different between the two groups. (10.5\% in the CABG group and $13.0 \%$ in the PCI group, $\mathrm{HR}=1.25, \mathrm{p}=0.39$ ). All-cause mortality rates were also similar (3.2\% for CABG and 3.2\% for PCI). The rates of death, MI, stroke, or repeat revascularization were $11.3 \%$ and 19.3\% (HR: 1.77, 95\% CI: 1.11 to 2.82; $\mathrm{p}=0.02$ ), respectively. When the patients who underwent CABG were compared with the subset of patients who received drug-eluting stents (69\% of patients), the primary outcome rates were $12.4 \%$ and $11.6 \%$ (HR: $0.93,95 \% \mathrm{CI}: 0.51$ to $1.71 ; \mathrm{p}=0.82$ ), respectively.

\subsubsection{ERACI II}

In this trial [16], a total of 450 patients with multi-vessel disease were randomly assigned to undergo either PCI $(n=225)$; or CABG $(n=225)$. Clinical follow-up during five years was obtained in $92 \%$ of the total population after hospital discharge. The primary end point of the study was to compare freedom from MACCE at 30 days, 1 year, 3 years, and 5 years of follow-up. At five years of follow-up, patients initially treated with PCI had similar survival and freedom from non-fatal acute myocardial infarction than those initially treated with CABG (92.8\% vs. $88.4 \%$ and $97.3 \%$ vs. $94 \%$ respectively, $p=0.16)$. Freedom from repeat revascularization procedures (PCI/CABG) was significantly lower with PCI compared with CABG (71.5\% vs. 92.4\%, p = 0.0002). Freedom from MACE was also significantly lower with PCI compared with CABG (65.3\% vs. 76.4\%; p = 0.013). At five years similar numbers of patients randomized to each revascularization procedure were asymptomatic or with class I angina. 


\subsubsection{AWESOME Trial (Angina with Extremely Serious Operative Mortality Evaluation)}

Patients from 16 Veterans Affairs Medical Centers were screened to identify myocardial ischemia refractory to medical management and the presence of one or more risk factors for adverse outcome with CABG, including prior open-heart surgery, age more than or equal to 70 years, left ventricular ejection fraction less than or equal to $35 \%$, myocardial infarction within seven days or intra-aortic balloon pump required. Clinically eligible patients $(\mathrm{n}=2431)$ underwent coronary angiography; 781 were angiographically acceptable; 454 (58\% of eligible) patients consented to random assignment between CABG $(\mathrm{n}=232)$ and PCI $(\mathrm{n}=222)$. The 30-day survivals for CABG and PCI were $95 \%$ and $97 \%$, respectively. Survival rates for CABG and PCI were $90 \%$ versus $94 \%$ at six months and $79 \%$ versus $80 \%$ at 36 months $(p=0.46)$ [17].

\subsubsection{FREEDOM Trial}

This trial [18] enrolled 1900 diabetic patients with multivessel coronary artery disease at 140 international centers. The patients were randomized to either PCI with DES or CABG. The patients were followed for a minimum of 2 years (median among survivors, 3.8 years). All patients were prescribed currently recommended medical therapies for the control of low-density lipoprotein cholesterol, systolic blood pressure, and glycated hemoglobin. The primary outcome measure was a composite of death from any cause, nonfatalmyocardial infarction, or nonfatal stroke. At 2 years, there was no difference in the primary outcomes between the two groups. However, at 5 years, the primary outcome occurred more frequently in the PCI group (26.6\%) compared to the CABG group $(18.7 \%)$, $(p=0.005)$. The benefit of CABG was driven by differences in rates of both myocardial infarction $(13.9 \%$ in PCI vs. $6 \%$ in CABG, $\mathrm{p}<0.001)$ and death from any cause $(16.3 \%$ in PCI vs. $10.9 \%$ in CABG, $p=0.049$ ). Stroke was more frequent in the CABG group ( $2.4 \%$ in PCI vs. $5.2 \%$ in CABG, $p=0.03$ ).

\subsubsection{PRECOMBAT-2 Trial (Premier of Randomized Comparison of Bypass Surgery versus Angioplasty Using Sirolimus-Eluting Stent in Patients with Left Main Coronary Artery Disease)}

This trial [19] looked at the 18-month incidence rates of MACCE, including death, MI, stroke, or ischemia-driven target vessel revascularization (TVR) in 334 consecutive patients who received everolimus-eluting stents (EES) for unprotected left main coronary artery stenosis between 2009 and 2010. These results were compared with those of a randomized study comparing patients who received sirolimus-eluting stents (SES) ( $\mathrm{n}=$ $327)$ or coronary artery bypass grafts $(\mathrm{CABG})(\mathrm{n}=272)$. EES $(8.9 \%)$ showed a comparable incidence of MACCE as SES (10.8\%; adjusted hazard ratio [aHR] of EES: 0.84 ; $95 \%$ confidence interval [CI]: 0.51 to 1.40; $\mathrm{p}=0.51)$ and CABG (6.7\%, aHR of EES: 1.40 ; $95 \%$ CI: 0.78 to 2.54; p $=0.26)$. The composite incidence of death, MI, or stroke also did not differ among patients receiving EES (3.3\%), SES (3.7\%; aHR of EES: 0.63; 95\% CI: 0.27 to 1.47; p = 0.29), and CABG (4.8\%; aHR of EES: 0.67; 95\% CI: 0.29 to 1.54; p $=0.34)$. However, the incidence of ischemia-driven TVR in the EES group (6.5\%) was higher than in the CABG group (2.6\%, aHR of EES: 2.77; 95\% CI: 1.17 to 6.58; $\mathrm{p}=0.02)$, but comparable to SES (8.2\%, aHR of EES: 1.14 ; 95\% CI: 0.64 to 2.06; $\mathrm{p}=0.65)$. Angiographic restenosis rates were similar in the SES and EES groups $(13.8 \%$ vs. $9.2 \%$, $\mathrm{p}=0.16)$.

\subsubsection{ULM (Unprotected Left Main)}

This trial [20] randomized 201 patients with ULM disease to undergo DES $(n=100)$ or CABG using predominantly arterial grafts $(n=101)$. The primary clinical end point was non-inferiority in freedom from MACCE, such as cardiac death, myocardial infarction, and the need for target vessel revascularization within 12 months. The combined primary end point was reached in $13.9 \%$ of patients after surgery, as opposed to $19.0 \%$ after PCI ( $\mathrm{p}=0.19$ for non-inferiority). The combined rates for death and myocardial infarction were comparable (surgery $7.9 \%$ vs. stenting, $5.0 \%$; non-inferiority $\mathrm{p}=0.001$ ), but stenting was inferior to surgery for repeat revascularization $(5.9 \%$ vs. $14.0 \%$; non-inferiority $\mathrm{p}=0.35)$. Perioperative complications including 2 strokes were higher after surgery ( $4 \%$ vs. $30 \% ; p=0.001)$. Freedom from angina was similar between groups $(p=0.33)$.

\subsection{Registries}

\subsubsection{Northern New England Registries}

A recent study compared long-term survival of patients with MVD treated with CABG or PCI [21]. From 
Northern New England registries of consecutive coronary revascularisations, the authors identified 10, 198 CABG and 4295 PCI patients with MVD who may have been eligible for either CABG or PCI between 1994 and 2001. CABG patients were older, had multiplecomorbidities, more triple-vessel disease, and lower ejection fractions, but were more completely revascularized [21]. Adjusted long-term survival for patients with triple vessel disease was superior following CABG (hazard ratio for mortality $0.60 ; p<0.01$ ), but not for patients with double-vessel disease (hazard ratio, 0.98; $\mathrm{p}=0.77$ ). The survival advantage of CABG for patients with triple-vessel disease was present in all patient populations, including diabetics and the elderly, and this is consistent with recent outcomes.

\subsubsection{New York's Cardiac Registries}

This registry [22] included almost 60,000 "real world" patients from New York's cardiac registries, including 37,212 patients with MVD disease who underwent CABG and 22,102 patients with MVD disease who underwent PCI from January 1, 1997, to December 31, 2000, adjusted data demonstrated a marked survival advantage for CABG patients over those who received PCI for double and triple-vessel disease and proximal LAD stenos is. It was shown that the risk-adjusted survival rates were significantly higher amongst patients who underwent CABG than amongst those who underwent PCI in all of the anatomical subgroups studied. Moreover, the three-year rates of revascularisation were considerably higher in the PCI group than in the CABG group (7.8\% vs. $0.3 \%$ for subsequent CABG and $27.3 \%$ vs. $4.6 \%$ for subsequent PCI). The observed (unadjusted) in-hospital mortality rate among the patients in the CABG group was significantly higher than the rate among patients who received a stent (1.75 percent [650 deaths] vs. 0.68 percent [150 deaths], $\mathrm{p}<0.001)$. The respective adjusted hazard ratios ranged from $0.76(\mathrm{p}=0.02)$ for patients with two-vessel disease and involvement of the non-proximal LAD artery to $0.64(\mathrm{p}<0.001)$ for patients with three-vessel disease and involvement of the proximal LAD artery. Significant risk factors in the statistical models included a lower ejection fraction; the presence of diabetes, congestive heart failure, chronic obstructive pulmonary disease, carotid-artery disease, aorto-iliac disease, shock, renal failure, femoral or popliteal disease, and stroke; advanced age; and male sex. After adjustment for the severity of illness before revascularization, CABG was associated with a significantly higher likelihood of survival in all anatomical groups.

\subsubsection{Intermountain Heart Registry}

A total of 6369 patients (CABG 4581; PCI-S 1788) were included in this registry [23] whom they had 5 years of follow-up, and had at least 2-vessel disease. Age averaged $66 \pm 10.9$ years, $76 \%$ were male, and $26 \%$ were diabetic. Multivariate risk favored CABG over PCI-S for both death (hazard ratio 0.85; $\mathrm{p}=0.001$ ) and major adverse cardiovascular events (hazard ratio $0.51 ; \mathrm{p}=0.0001$ ). A similar advantage with CABG was also found in most substrata, including diabetes. The only subgroups in which the survival advantage trended toward PCI-S were those with a previous history of coronary revascularization (either previous CABG or PCI). CABG patients also experienced fewer repeat revascularizations (CABG or PCI) and MI and $41 \%$ fewer events for the composite end point of MACE.

\subsubsection{CREDO-Kyoto PCI/CABG Registry}

This registry [24] enrolled 1005 patients with ULMCAD of 15,939 patients with first coronary revascularization enrolled in the CREDO-Kyoto PCI/CABG Registry Cohort-2. Cumulative 3-year incidence of a composite of death/myocardial infarction (MI)/stroke was significantly higher in the PCI group than in the CABG group ( $22.7 \%$ vs. $14.8 \%, p=0.0006$, log-rank test). However, the adjusted outcome was not different between the PCI and CABG groups (hazard ratio [HR] 1.30, 95\% confidence interval [CI] 0.79 to $2.15, \mathrm{p}=0.30$ ). Stratified analysis using the SYNTAX score demonstrated that risk for a composite of death/MI/stroke was not different between the 2 treatment groups in patients with low $(<23)$ and intermediate (23 to 33) SYNTAX scores (adjusted HR 1.70, 95\% CI 0.77 to $3.76, p=0.19$; adjusted HR $0.86,95 \%$ CI 0.37 to $1.99, p=0.72$, respectively), whereas in patients with a high SYNTAX score $(>33)$, it was significantly higher after PCI than after CABG (adjusted HR 2.61, 95\% CI 1.32 to 5.16, $\mathrm{p}=0.006$ ). In conclusion, risk of PCI for serious adverse events seemed to be comparable to that after CABG in patients with ULMCAD with a low or intermediate SYNTAX score, whereas PCI compared with CABG was associated with a higher risk for serious adverse events in patients with a high SYNTAX score. 


\subsubsection{The DELTA Registry}

A total 2775 patients were included in this registry [25]: 1874 were treated with PCI versus 901 with CABG. At1, 295 (interquartile range: 928 to 1713) days, there were no differences, at the adjusted analysis, in the primary composite endpoint of death, cerebrovascular accidents, and myocardial infarction (MI) (adjusted hazard ratio [HR]: 1.11; 95\% confidence interval [CI]: 0.85 to 1.42; $\mathrm{p}=0.47$ ), mortality (adjusted HR: 1.16; 95\% CI: 0.87 to 1.55; $\mathrm{p}=0.32$ ), or composite endpoint of death and MI (adjusted HR: $1.25 ; 95 \% \mathrm{CI}$ : 0.95 to 1.64; $\mathrm{p}=$ 0.11). An advantage of CABG over PCI was observed in the composite secondary endpoint of MACCE (adjusted HR: 1.64; 95\% CI: 1.33 to 2.03; $\mathrm{p}=0.0001$ ), driven exclusively by the higher incidence of target vessel revascularization with PCI.

At Cox regression multivariable analysis, age (1.03; 95\% CI: 1.00 to $1.04 ; \mathrm{p}=0.009)$, Euro SCORE (1.06; 95\% CI: 1.01 to 1.10 ; $\mathrm{p}=0.02)$, SYNTAX score $(1.02$; $95 \% \mathrm{CI}: 1.01$ to 1.03 ; $\mathrm{p}=0.0001)$, emergency procedures (0.68; 95\% CI: 0.48 to 0.95; p = 0.02), and need for intra-aortic balloon pump (IABP) (1.85, 95\% CI: 1.27 to 2.68; $\mathrm{p}=0.001$ ) were found to be predictors of the composite primary endpoint of death, MI, and CVA Predictors of death were age (1.03; 95\% CI: 1.01 to 1.05 ; $\mathrm{p}=0.001)$, $\operatorname{LVEF}(0.98,95 \%$ CI: 0.97 to 0.99 ; $\mathrm{p}=0.02)$, SYNTAX score $(1.03,95 \% \mathrm{CI}: 1.02$ to $1.04 ; \mathrm{p}=0.0001)$, presentation with acute MI (1.62; 95\% CI: 1.03 to 2.53; $\mathrm{p}=0.04)$, and the need for IABP support (2.0; 95\% CI: 1.35 to 2.97; $\mathrm{p}=0.001)$. Predictors of MACCE were PCI (1.38; 95\% CI: 1.01 to 1.89; $\mathrm{p}=0.046)$, Euro SCORE $(1.05 ; 95 \%$ CI: 1.02 to 1.09 ; $\mathrm{p}=0.005$ ), SYNTAX score (1.01; 95\% CI: 1.01 to 1.02 ; $\mathrm{p}=0.0001)$, need for IABP support (2.06; 95\% CI: 1.52 to 2.79; $\mathrm{p}$ $=0.0001)$, and distal ULMCA disease (1.34; 95\% CI: 1.04 to $1.72 ; \mathrm{p}=0.02)$.

\subsubsection{The LE MANS (Left Main Coronary Artery Stenting) Registry}

This multicenter prospective registry [26] included 252 patients after ULMCA stenting enrolled between March 1997 and February 2008. Non-ST-segment elevation acute coronary syndrome was diagnosed in 58\% of patients; ST segment elevation myocardial infarction cases were excluded. Drug-eluting stents were implanted in $36.2 \%$ of patients. MACCE occurred in 12 (4.8\%) patients during the 30-day period, which included 4 (1.5\%) deaths. After 12 months there were 17 (12.1\%) angiographically confirmed cases of restenosis. During long-term follow-up (1 to 11 years, mean 3.8 years) there were 64 (25.4\%) MACCE and 35 (13.9\%) deaths. The 5- and 10 -year survival rates were $78.1 \%$ and $68.9 \%$, respectively. Despite differences in demographical and clinical data in favor of BMS patients, unmatched analysis showed a significantly lower MACCE rate in DES patients ( $25.9 \%$ vs. $14.9 \%, p=0.039$ ). This difference was strengthened after propensity score matching. The DES lowered both mortality and MACCE for distal ULMCA lesions when compared with BMS. Ejection fraction $<50 \%$ was the only independent risk factor influencing long-term survival.

There was significantly better long-term survival in patients with isolated LM or LM with 1- and 2-vessel disease when compared with LM with 3-vessel disease (Cox p $=0.02, \mathrm{p}=0.005, \mathrm{p}=0.008$, respectively). The univariate predictors of death were: age $>60$ years ( $\mathrm{p}=0.03$, OR: $2.48,95 \% \mathrm{CI}: 1.03$ to 5.95$)$, LVEF $<50 \%$ (p $=0.01$, OR: 3.25 , 95\% CI: 1.45 to 7.27$)$ and Euro SCORE on admission $>9$ (p $=0.04$, OR: 2.48, 95\% CI: 1.1 to 4.56). The Cox multivariate analysis for independent risk factors showed that LVEF $<50 \%$ decreased survival rate, whereas DES implantation decreased and stent diameter $<3.8 \mathrm{~mm}$ increased the risk of MACCE.

Comparison of the patient subsets with stenosis of distal $(n=149)$ versus proximal and/or medial LM showed no significant differences among demographical, clinical, and procedural data among those groups except a higher number of implanted DES (45.6\% vs. $24.3 \%, \mathrm{p}=0.001)$, a higher number of diseased vessels $(2.2 \pm 0.8$ vs. $1.8 \pm 1, \mathrm{p}=0.0002)$, and more lesions $(1.6 \pm 1$ vs. $1.1 \pm 0.9, \mathrm{p}=0.0006)$ in patients with distal LM disease. Kaplan-Meier analysis showed no difference in survival and MACCE-free survival among these subsets.

\subsection{Meta-Analyses and Systematic Reviews}

\subsubsection{Multivessel Disease}

Results of meta-analyses and systematic reviews are consistent in some lesions and some patient populations and inconsistent in others. These results depend on the date of the publication and the studies included in that era. A meta-analysis of 24,268 patients with MVD [27] who underwent DES-PCI $(n=13,540)$ and CABG ( $n=$ 10,728 ) from nine observational nonrandomized studies showed that DES and CABG were comparable in terms of composite occurrence of death, acute myocardial infarction and cerebrovascular accidents (HR $=0.94 ; 95 \%$ $\mathrm{CI}=0.72-1.22 ; \mathrm{p}=0.66$ ). However, there was a significantly higher risk of repeat revascularization in the DES 
group $(\mathrm{HR}=4.06 ; 95 \% \mathrm{CI}=2.64-6.24 ; \mathrm{p}<0.001)$. Overall major adverse cardiac and cerebrovascular events rate in the DES-PCI was higher compared to the CABG group ( $\mathrm{HR}=1.86$; 95\% CI $=1.36-2.54$; $\mathrm{p}<0.001)$.

A systematic review of 23 clinical trials that included almost 10,000 patients [28] showed that difference in survival after PCI or CABG was less than $1 \%$ over 10 years of follow-up. Survival did not differ between PCI and CABG for patients with diabetes in the 6 trials that reported on this subgroup. Procedure-related strokes were more common after CABG than after PCI (1.2\% vs. $0.6 \%$; risk difference, $0.6 \%$; $\mathrm{p}=0.002)$. Angina relief was greater after CABG than after PCI, with risk differences ranging from $5 \%$ to $8 \%$ at 1 to 5 years $(\mathrm{p}=0.001)$. The absolute rates of angina relief at 5 years were $79 \%$ after PCI and $84 \%$ after CABG. Repeated revascularization was more common after PCI than after CABG (risk difference, $24 \%$ at 1 year and $33 \%$ at 5 years; $\mathrm{p}=$ 0.001); the absolute rates at 5 years were $46.1 \%$ after balloon angioplasty, $40.1 \%$ after PCI with stents, and $9.8 \%$ after CABG. It should be noted that only about one third of patients had true triple-vessel disease, most patients had an ejection fraction of more than 50\%, there were no patients with left main stem stenos is, and only about $40 \%$ of patients had proximal LAD disease. Thus the vast majority of these patients had single-vessel or double vessel disease and normal left ventricular function, a population in whom it had already been clearly established that there was no prognostic benefit to be gained from CABG.

Another systematic review [29] that included only Trials with multivessel or single-vessel (proximal LAD) disease showed that for patients with MVD, risk of death was lower in the CABG-treated patients at five years (RD 2.3\%, CI $0.29 \%$ to $4.3 \%, \mathrm{p}=0.025$ ) and at eight years (RD 3.4\%, CI $0.32 \%$ to $6.4 \%$, $\mathrm{p}=0.03$ ). Similarly, CABG lowered cardiac death at year 5 (RD $2.4 \%$, CI $0.44 \%$ to $4.3 \%, \mathrm{p}=0.016)$. For those with single-vessel proximal LAD disease, the risk of death was lower in CABG-treated patients at year 5 (RD 5.6\%, CI $0.19 \%$ to $11 \%, p=0.042$ ), but there was no statistically significant difference in all-cause mortality at year 3 .

The effect of Diabetic status and age were illustrated in a meta-analysis [30] that included 10 trials with data on 7812 patients. PCI was done with balloon angioplasty in six trials and with bare-metal stents in four trials. Over a median follow-up of 5.9 years (IQR 5.0 - 10.0), 575 (15\%) of 3889 patients assigned to CABG died compared with 628 (16\%) of 3923 patients assigned to PCI (hazard ratio [HR] 0.91, 95\% CI 0.82 - 1.02; $\mathrm{p}=$ 0.12). In patients with diabetes (CABG, $n=615 ; \mathrm{PCI}, \mathrm{n}=618$ ), mortality was substantially lower in the CABG group than in the PCI group (HR 0.70, 0.56 - 0.87); however, mortality was similar between groups in patients without diabetes (HR 0.98, $0.86-1.12 ; \mathrm{p}=0.014$ for interaction). Patient age modified the effect of treatment on mortality, with hazard ratios of 1.25 (0.94 - 1.66) in patients younger than 55 years, 0.90 (0.75 - 1.09) inpatients aged 55 - 64 years, and $0.82(0.70-0.97)$ in patients 65 years and older ( $\mathrm{p}=0.002$ for interaction). Treatment effect was not modified by the number of diseased vessels or other baseline characteristics.

A recent meta-analysis of 6 randomized trials [31] enrolling a total of 6055 patients, with a weighted average follow-up of 4.1 years showed that there was a significant reduction in total mortality with CABG compared with PCI $(\mathrm{RR}=0.73$ [95\% CI, $0.62-0.86])(\mathrm{p}<0.001)$. There were also significant reductions in myocardial infarction $(\mathrm{RR}=0.58$ [95\% CI, $0.48-0.72])(\mathrm{p}<0.001)$ and repeat revascularization $(\mathrm{RR}=0.29$ [95\% CI, 0.21 - 0.41]) $(\mathrm{p}<0.001)$ with CABG. There was a trend toward excess strokes with CABG (RR $=1.36$ [95\% CI, 0.99 - 1.86]), but this was not statistically significant $(p=0.06)$. The absolute risk increase in stroke was small compared with the absolute risk reduction in mortality and MI, as demonstrated by the numbers needed to treat. For reduction in total mortality, there was no heterogeneity between trials that were limited to and not limited to patients with diabetes or whether stents were drug eluting or not.

\subsubsection{Unprotected LM Disease}

Clinical outcomes for unprotected left main coronary artery (ULMCA) disease between coronary artery bypass grafting (CABG) and drug-eluting stents (DESs) remain controversial. The proximal location of the left main coronary artery and its relatively large diameter make it, in theory, an attractive target for stenting. However, in reality, several anatomic features severely diminish the likelihood of a successful long-term outcome with PCI. Up to $90 \%$ of left main stemstenoses extend from the distal left main stem branch into the proximal left anterior descending and/or circumflex coronary arteries and such bifurcating lesions are at notoriously high risk of restenosis after stenting [32] [33]. Furthermore, up to $80 \%$ of patients with left main stem disease also have multi-vessel coronary artery disease, where coronary revascularisation with CABG already offers a survival advantage [34]. Approximately $15 \%-20 \%$ of percutaneous coronary interventions are performed to treat bifurcation lesions [35] [36]. Thus, despite recent advances in interventional cardiology and the introduction of DES, stenting of bifurcation lesions remains technically challenging, with lower procedural success rates and worse clini- 
cal outcomes than non-bifurcation lesions, whereas CABG is equally effective in dealing with bifurcation and non-bifurcation lesions alike [37].

A meta-analysis of twelve clinical studies (3 randomized trials and 9 observational studies) [38] with 5079 patients compared the safety and efficacy of percutaneous coronary intervention (PCI) using DESs with CABG in patients with ULMCA disease. End points of this meta-analysis were mortality; composite of death, myocardial infarction (MI), or stroke; and target vessel revascularization at 1-year follow up. At 1-year follow-up, there were trends toward lower risk of death (odds ratio [OR] 0.68, 95\% confidence interval [CI] 0.45 to 1.02) and the composite end point of death, MI, or stroke (OR 0.70, 95\% CI 0.49 to 1.00) in the DES group compared to the CABG group. However, target vessel revascularization was significantly higher in the DES group compared to the CABG group (OR 3.52, 95\% CI 2.72 to 4.56).

Pooled effects showed no significant difference in the incidence of death at 1 year (OR 0.68, 95\% CI 0.45 to 1.02). The number needed to treat to prevent 1 death with DES was 50 . None of the studies influenced the results to an extent that the conclusion would have changes: sensitivity analysis of risk of death after exclusion of 1 study at a time yielded effect sizes similar in magnitude and direction to overall estimates. Risk for composite end point of death, MI, or stroke was lower in the DES group (6.12\%) compared to the CABG group (9.39\%) with marginal statistical significance (OR $0.70,95 \%$ CI 0.49 to 1.00 ). Thirty-three patients were needed to treat with DESs to avoid composite endpoint of death, MI, or stroke. There was evidence of moderate statistical heterogeneity among included studies. In stratified analysis of SYNTAX LMCA [39] and PRECOMBAT [40] trials by burden of coronary artery diseases,1-year rates of composite end point of death, MI, or stroke were not different with DESs compared to those for CABG for isolated LMCA disease (OR 0.23, 95\% CI 0.03 to 2.00), LMCA with 1-vessel disease (OR 0.53, 95\% CI 0.14 to 2.02), LMCA with 2-vessel disease (OR 0.99, 95\% CI 0.45 to 2.17 ), and LMCA with 3-vessel disease (OR $0.80,95 \%$ CI 0.41 to 1.55 ). Similarly, stratified analysis of rates of target vessel revascularization by disease burden demonstrated a similar risk with DESs compared to CABG for isolated LMCA disease (OR 0.89, 95\% CI 0.21 to 3.76), LMCA with 1-vessel disease (OR 0.61, 95\% CI 0.14 to 2.59), and LMCA with 2-vessel disease (OR 1.80, 95\% CI 0.89 to 3.64), but a significantly higher risk with DESs in patients with LMCA with 3-vessel disease (OR 2.98, 95\% CI 1.42 to 6.27).

Another meta-analysis [41] compared the safety and efficacy of DESs to coronary artery bypass grafting (CABG) in real-world patients with unprotected left main coronary artery. It included 25 observational studies representing 7230 patients from January 2000 through May 2012. Data were grouped according to follow-up times of $<2,<3$, and $>3$ years. No differences were detected between CABG and DES in overall mortality ( $<2$ years, adjusted risk ratio [RR], 0.83 , 95\% confidence interval [CI] 0.53 to 1.28 ; $<3$ years, adjusted RR $0.60,95 \%$ CI 0.20 to 1.66; $>3$ years, adjusted RR $0.58,95 \%$ CI 0.29 to 1.17) or in MACCE ( $<2$ years, adjusted RR 1.22, $95 \%$ CI 0.86 to 1.73 ; <3 years, adjusted RR 1.70, 95\% CI 1.35 to 2.15 ; >3 years, adjusted RR1.23, 95\% CI 0.87 to 1.73). Compared to DESs, CABG showed a significant decrease in target vessel revascularization ( $<2$ years, adjusted RR 3.72, 95\% CI 2.50 to 5.52; $<3$ years, adjusted RR 3.92, 95\% CI 2.54 to 6.04 ; $>3$ years, adjusted RR 3.45 , 95\% CI 2.14 to 5.57 ).

The same findings were also shown by another meta-analysis by Capodanno et al. [42] that included 1611 patients from 4 randomized clinical trials. PCI was associated with a non-significantly higher 1-year rate of MACCE compared with CABG (14.5\% vs. 11.8\%; odds ratio [OR]: 1.28; 95\% confidence interval [CI]: 0.95 to 1.72; $\mathrm{p}=0.11)$, driven by increased TVR $(11.4 \%$ vs. $5.4 \%$; OR: 2.25 ; $95 \%$ CI: 1.54 to 3.29 ; p $=0.001)$. Conversely, stroke occurred less frequently with PCI (0.1\% vs. $1.7 \%$; OR: 0.15 ; $95 \%$ CI: 0.03 to $0.67 ; \mathrm{p}=0.013)$. There were no significant differences in death (3.0\% vs. $4.1 \%$; OR: $0.74 ; 95 \% \mathrm{CI}: 0.43$ to $1.29 ; \mathrm{p}=0.29)$ or MI (2.8\% vs. $2.9 \%$; OR: 0.98 ; $95 \%$ CI: 0.54 to $1.78 ; \mathrm{p}=0.95$ ).

\subsubsection{Diabetes Mellitus}

A meta-analysis of 4 trials [29] reporting outcomes in diabetic patients reported that at 4 years, CABG was favored over PTCA for preventing all-cause death (RD 8.6\%, CI $2.2 \%$ to $15 \%, \mathrm{p}=0.01$ ), but after 6.5 years, CABG was no longer significantly favored (RD $3.9 \%$, CI $17 \%$ to $25 \%, p=0.71$ ). For non-diabetic patients, there was no significant difference in survival at 4 or 6.5 years.

The same findings were shown by another meta-analysis of 14 (4 randomized and 10 non-randomized) trials [43] with a total of 7072 patients. Up to 5 years follow-up, CABG was associated with a reduction in mortality (7.3\% vs $10.4 \%$, OR [95\% CI] $=0.65[0.55-0.77], \mathrm{p}<0.0001$; phet $=0.00001)$, with similar results in both RCTs $(\mathrm{OR}[95 \% \mathrm{CI}]=0.64[0.50-0.82], \mathrm{p}=0.0005)$ and NRCTs $(\mathrm{OR}[95 \% \mathrm{CI}]=0.75[0.6-0.94)], \mathrm{p}=0.01)$ 
$(\mathrm{p}=0.93)$. A significant relationship was observed between risk profile and benefits in mortality with CABG (p $<0.001$ ). CABG reduced target vessel revascularization (TVR; $5.2 \%$ vs. $15.7 \%$, OR [95\% CI] $=0.30[0.25-$ 0.36], $\mathrm{p}<0.00001, \mathrm{p}=0.02$ ), with a relationship between risk profile and the benefits from CABG as compared to DES (p < 0.0001). CABG was associated with a lower rate of MACCE $(14.9 \%$ vs. $22.9 \%$, OR $[95 \% \mathrm{CI}]=$ 0.59 [0.51 - 0.67], $\mathrm{p}<0.00001, \mathrm{p}<0.00001)$ but higher risk of CVA (3.6\% vs. $1.4 \%$, OR [95\% CI] $=2.34[1.63$ - 3.35], $\mathrm{p}<0.00001, \mathrm{p}=0.71$.

Another study of 7159 consecutive patients with diabetes [44] who underwent coronary revascularization in northern New England during 1992 to 1996, showed similar findings. Patients with diabetes treated with PCI had significantly greater mortality relative to those undergoing CABG (HR 5 1.49; CI 95\%: 1.02 to 2.17; $\mathrm{p}=$ 0.037). Mortality risk tended to increase more among 1251 patients with 3VD (HR 5 2.02; CI 95\%: 1.04 to 3.91; $\mathrm{p}=0.038$ ) than among 1515 patients with 2 VD (HR 5 1.33; CI 95\%: 0.84 to 2.1; $\mathrm{p}=0.21$ ).

\subsubsection{Age}

Pooled analysis of 4 stent trials [45] (ARTS [Arterial Revascularization Therapies Study], ERACI II [second Argentine randomized trial of percutaneous transluminal coronary angioplasty versus coronary artery bypass surgery in multivessel disease], MASS II [Second Medicine, Angioplasty, or Surgery Study], and SoS [Stent or Surgery] showed that older patients had more procedural complications, especially stroke. Long-term survival after PCI or CABG did not differ significantly among patient solder than 65 years of age compared with younger patients, but very few patients older than 75 years of age were enrolled.

\subsubsection{High Risk Patients}

In New York Registry [22], the unadjusted survival estimates favored PCI and adjusted survival estimates favored CABG for patients with two-vessel disease without LAD-artery involvement. This can be explained by the fact that the prevalences of several important risk factors were much higher in the CABG group than in the stenting group (e.g., 3.4 percent vs. 2.2 percent for renal failure, 16.4 percent vs. 5.9 percent for chronic obstructive pulmonary disease, and 12.3 percent vs. 7.0 percent for congestive heart failure). When the subgroup of patients with diabetes was analyzed, the adjusted hazard ratios were lower after CABG than after stenting in all anatomical subgroups except patients who had three-vessel disease with involvement of the proximal LAD artery (0.69; 95 percent confidence interval, 0.55 to 0.86 ). For patients with a left ventricular ejection fraction below40 percent, the hazard ratios were significantly in favor of CABG, as compared with stenting, for patients with three-vessel disease and patients with two-vessel disease with involvement of the proximal LAD artery, but the hazard ratios were not significant for the other patients with two-vessel disease. For patients with no left ventricular dysfunction (as defined by an ejection fraction of at least 40 percent), CABG was associated with significantly lower adjusted hazard ratios in all anatomical groups.

In propensity analysis of long term survival of patients with high risk features [46], there were 2319 patients (265 PCI, 2054 CABG) with diabetes. Among the 1504 non-insulin-treated diabetics, there were 270 deaths (18\%), and PCI was associated with an increased risk (21\% versus 17\%; adjusted hazard ratio, 1.7; 95\% CI, 1.2 to 2.5; $\mathrm{p}=0.008)$. Among the 815 insulin-treated diabetics, there were 198 deaths $(24 \%)$, and PCI again was associated with an increased risk of death (31\% versus 23\%; adjusted hazard ratio, 2.6; 95\% CI, 1.7 to 3.9; $\mathrm{p}=$ 0.0001). Among 627 patients with an ejection fraction $<30 \%$, there were 183 deaths $(29 \%)$. The 5-year death rate tended to be higher for PCI ( $37 \%$ versus $28 \%$; adjusted hazard ratio, 1.6; $95 \%$ CI, 0.9 to 2.7 ; p = 0.09).

\subsubsection{Guidelines and Appropriateness Revascularization Criteria}

The 2010 ESC guidelines for myocardial revascularization [47] provide a class I recommendation: a) for prognosis in patients with hemodynamically significant disease and LM involvement, single remaining patent vessel, proximal LAD disease, MVD and reduced EF and also for patients exhibiting a large ischemic territory; b) for symptoms despite OMT in patients with limiting angina or its equivalents (class I) and those with heart failure and ischemia or viability (class IIa). For MVD, the European guidelines recommend PCI for patients with 2-VD without or with proximal LAD disease at a class I and IIa level of recommendation, respectively. Patients with 3-VD, simple anatomy, achievable complete revascularization and low SYNTAX scores are provided a IIa class indication for PCI, while patients with complex 3-VD, SYNTAX score N22 and/or unobtainable complete revascularization are considered as not suitable for PCI. Moreover, PCI for LM stem disease has a class IIa indication for ostial or shaft lesions (either isolated or in the presence of 1-VD), IIb indication for isolated distal dis- 
ease or with co-existing 1-VD and is considered to be contraindicated in patients with additional MVD and calculated SYNTAX score N32. CABG in contrast, has a class I indication for revascularization in every patient with LM disease. The 2009 US perioperative guidelines for non-cardiac surgery [48] recommend revascularization for stable angina before non-cardiac surgery in patients with 3-VD or 2-VD with proximal LAD involvement and LVEF b 50\% or positive stress test (Class I recommendation). Likewise, the updated 2009 AHA/ACC guidelines [49] have revised their class III to a class IIb recommendation for PCI in unprotected LM disease in selected cases. CABG is deemed appropriate regardless of LV function and diabetic status. In contrast, PCI is considered appropriate only for 2-VD patients, whether or not they are diabetics and whether or not they have depressed LV function. PCI has uncertain indication for 3-VD without LM involvement [50]. Currently and at variance with European reports [51], patients with CAD receive more recommendations for PCI and fewer recommendations for CABG treatment than indicated in the US guidelines [52] depending on non-angiographic as well as angiographic factors [53].

\section{Conclusion}

This review illustrates the need for careful patient and lesion selection. Patients with complex MVD as compared with those who have less complex anatomy demonstrate more MACCE with PCI but not with CABG mainly because of the need for repeat revascularization. The SYNTAX score is very useful for selected 3-VD or LM disease patients to determine the best revascularization mode and as a communication tool between surgeons and cardiologists. By incorporating clinical and other information (such as age, diabetes, renal dysfunction and LVEF), MACE predictability may improve over SYNTAX anatomic information, but further validation in other independent datasets is certainly required. It appears that patients with complex coronary anatomy derive the greatest benefit from the completeness of revascularization and therefore from surgery over PCI. However, simpler CAD can offer PCI, even if complete revascularization is not possible. In addition to the complexity of the lesion, patients' characteristics are important. At present, the totality of evidence suggests that CABG appears better for the "sicker" patients, i.e., those with MVD and characteristics indicative of extensive atheroma burden (anatomically extensive disease, advanced age or DM, especially in combination with insulin-sensitizing therapy and high-risk ischemic territories) with or without depressed LVEF. In low-risk patients, PCI demonstrates an equivalent to CABG safety profile. The currently almost exclusive use of DES seems to be associated with lower mortality, MI and TLR rates in comparison with the older BMS series. Because of the narrow margin for error, the importance of both operator experience and their back-up by highly competent support staff and surgeons should be strengthened. We would additionally emphasize the involvement of the Heart Team for a joint assessment and consensus regarding revascularization therapy on a routine basis for all LM and MV disease patients. The Heart Team should optimize decision made by calculating surgical risk (e.g., Euroscore etc.) and determine whether complete revascularization is achievable. This approach indicates the need to avoid adhoc PCI in patients with complex CAD and further enables first, a clear decision for a one-way revascularization treatment option in a substantial proportion of them and second, the discussion with the rest, probably the majority of the patients about their alternative choice for either PCI or CABG.

\section{References}

[1] Mehta, S.R., Cannon, C.P., Fox, K.A., et al. (2005) Routine vs Selective Invasive Strategies in Patients with Acute Coronary Syndromes: A Collaborative Meta-Analysis of Randomized Trials. JAMA, 293, 2908-2917. http://dx.doi.org/10.1001/jama.293.23.2908

[2] Hachamovitch, R., Hayes, S.W., Friedman, J.D., Cohen, I. and Berman, D.S. (2003) Comparison of the Short-Term Survival Benefit Associated with Revascularization Compared with Medical Therapy in Patients with No Prior Coronary Artery Disease Undergoing Stress Myocardial Perfusion Single Photon Emission Computed Tomography. Circulation, 107, 2900-2907. http://dx.doi.org/10.1161/01.CIR.0000072790.23090.41

[3] Shaw, L.J., Berman, D.S., Maron, D.J., et al. (2008) Optimal Medical Therapy with or without Percutaneous Coronary Intervention to Reduce Ischemic Burden: Results from the Clinical Outcomes Utilizing Revascularization and Aggressive Drug Evaluation (COURAGE) Trial Nuclear Substudy. Circulation, 117, 1283-1291. http://dx.doi.org/10.1161/CIRCULATIONAHA.107.743963

[4] Katritsis, D.G. and Ioannidis, J.P. (2007) PCI for Stable Coronary Disease. New England Journal of Medicine, 357, 414-415. http://dx.doi.org/10.1056/NEJMc071317

[5] Serruys, P.W., Morice, M.C., Kappetein, A.P., Colombo, A., Holmes, D.R., Mack, M.J., Ståhle, E., Feldman, T.E., 
Van den Brand, M., Bass, E.J., Dyck, N.V., Leadley, K., Dawkins, K.D. and Mohr, F.W. (2009) For the SYNTAX Investigators. Percutaneous Coronary Intervention versus Coronary-Artery Bypass Grafting for Severe Coronary Artery Disease. New England Journal of Medicine, 360, 961-972. http://dx.doi.org/10.1056/NEJMoa0804626

[6] Banning, A.P., Westaby, S., Morice, M.C., Kappetein, A.P., Mohr, F.W., Berti, S., Glauber, M., Kellett, M.A., Kramer, R.S., Leadley, K., Dawkins, K.D. and Serruys, P.W. (2010) Diabetic and Nondiabetic Patients with Left Main and/or 3-Vessel Coronary Artery Disease Comparison of Outcomes with Cardiac Surgery and Paclitaxel-Eluting Stents. Journal of the American College of Cardiology, 55, 1067-1075. http://dx.doi.org/10.1016/j.jacc.2009.09.057

[7] Kappetein, A.P., Feldman, T.E., Mack, M.J., Morice, M.C., Holmes, D.R., Stahle, E., Dawkins, K.D., Mohr, F.W., Serruys, P.W. and Colombo, A. (2011) Comparison of Coronary Bypass Surgery with Drug-Eluting Stenting for the Treatment of Left Main and/or Three-Vessel Disease: 3-Year Follow-Up of the SYNTAX Trial. European Heart Journal, 32, 2125-2134. http://dx.doi.org/10.1093/eurheartj/ehr213

[8] The BARI Investigators (2000) Seven-Year Outcome in the Bypass Angioplasty Revascularization Investigation (BARI) by Treatment and Diabetic Status. Journal of the American College of Cardiology, 35, 1122-1129. http://dx.doi.org/10.1016/S0735-1097(00)00533-7

[9] The BARI Investigators (2007) The Final 10-Year Follow-Up Results from the BARI Randomized Trial. Journal of the American College of Cardiology, 49, 1600-1606. http://dx.doi.org/10.1016/j.jacc.2006.11.048

[10] King $3^{\text {rd }}$, S.B., Kosinski, A.S., Guyton, R.A., Lembo, N.J. and Weintraub, W.S. (2000) Eight-Year Mortality in the Emory Angioplasty versus Surgery Trial (EAST). Journal of the American College of Cardiology, 35, 1116. http://dx.doi.org/10.1016/S0735-1097(00)00546-5

[11] Investigators SoS (2002) Coronary Artery Bypasses Surgery versus Percutaneous Coronary Intervention with Stent Implantation in Patients with Multivessel Coronary Artery Disease (the Stent or Surgery Trial): A Randomized Controlled Trial. Lancet, 360, 965. http://dx.doi.org/10.1016/S0140-6736(02)11078-6

[12] Abizaid, A., Costa, M.A., Centemero, M., Abizaid, A.S., Legrand, V.M., Limet, R.V., et al. (2001) Clinical and Economic Impact of Diabetes Mellitus on Percutaneous and Surgical Treatment of Multivessel Coronary Disease Patients: Insights from the Arterial Revascularization Therapy Study (ARTS) Trial. Circulation, 104, 533. http://dx.doi.org/10.1161/hc3101.093700

[13] Serruys, P.W., Andrew, T.L., Ong, A.L., Herwerden, L.A., Sousa, J.E., Jatene, A., Johannes, J.R.M., Bonnier, J., Jacques, P.M.A., Schönberger, J., Buller, N., Bonser, R., Disco, C., Backx, B., Hugenholtz, P.G., Firth, B.G. and Unger, F. (2005) Five-Year Outcomes after Coronary Stenting versus Bypass Surgery for the Treatment of Multivessel Disease the Final Analysis of the Arterial Revascularization Therapies Study (ARTS) Randomized Trial. Journal of the American College of Cardiology, 46, 575-581. http://dx.doi.org/10.1016/j.jacc.2004.12.082

[14] Daemen, J., Kuck, K.H., Macaya, C., LeGrand, V., Vrolix, M., Carrie, D., Sheiban, I., Suttorp, M.J., Vranckx, P., Rademaker, T., Goedhart, D., Schuijer, M., Wittebols, K., Macours, N., Stoll, H.P. and Serruys, P.W. (2008) On Behalf of the ARTS-II Investigators. Multivessel Coronary Revascularization in Patients with and without Diabetes Mellitus 3-Year Follow-Up of the ARTS-II Trial. Journal of the American College of Cardiology, 52, 1957-1967. http://dx.doi.org/10.1016/j.jacc.2008.09.010

[15] Kapur, A., Hall, R.J., Malik, I.S., Qureshi, A.C., Butts, J., de Belder, M., Baumbach, A., Angelini, G., de Belder, A., Oldroyd, K.G., Flather, M., Roughton, M., Nihoyannopoulos, P., Bagger, J.P., Morgan, K. and Beatt, K.J. (2010) Randomized Comparison of Percutaneous Coronary Intervention with Coronary Artery Bypass Grafting in Diabetic Patients 1-Year Results of the CARDia (Coronary Artery Revascularization in Diabetes) Trial. Journal of the American College of Cardiology, 55, 432-440. http://dx.doi.org/10.1016/j.jacc.2009.10.014

[16] Rodriguez, A.E., Baldi, J., Pereira, C.F., Navia, J., Alemparte, M.R., Delacasa, A., Vigo, F., Vogel, D., O’Neill, W., Palacios, I.F. and ERACI II Investigators (2005) Five-Year Follow-Up of the Argentine Randomized Trial of Coronary Angioplasty with Stenting versus Coronary Bypass Surgery in Patients with Multiple Vessel Disease (ERACI II). Journal of the American College of Cardiology, 46, 582-588. http://dx.doi.org/10.1016/j.jacc.2004.12.081

[17] Morrison, D.A., Sethi, G., Sacks, J., Henderson, W., Grover, F., Sedlis, S., Esposito, R., Ramanathan, K., Weiman, D., Saucedo, J., Antakli, T., Paramesh, V., Pett, S., Vernon, S., Birjiniuk, V., Welt, F., Krucoff, M., Wolfe, W., Lucke, J.C., Mediratta, S., Booth, D., Barbiere, C., Lewis, D. and Investigators of the Angina with Extremely Serious Operative Mortality Evaluation (AWESOME) (2001) Percutaneous Coronary Intervention versus Coronary Artery Bypass Graft Surgery for Patients with Medically Refractory Myocardial Ischemia and Risk Factors for Adverse Outcomes with Bypass: A Multicenter, Randomized Trial. Journal of the American College of Cardiology, 38, 143-149.

[18] Farkouh, M.E., Domanski, M., Sleeper, L.A., Siami, F.S., Dangas, G.M.D., Mack, M., Yang, M., Cohen, D.J., Rosenberg, Y., Solomon, S.D., Desai, A.S., Gersh, B.J., Magnuson, E.A., Lansky, A., Boineau, R., Weinberger, J., Ramanathan, K., Sousa, J.E., Rankin, J., Bhargava, B., Buse, J., Hueb, W., Smith, C.R., Muratov, V., Bansilal, S., King III, S., Bertrand, M., Fuster, V. and FREEDOM Trial Investigators (2012) Strategies for Multivessel Revascularization in Patients with Diabetes. New England Journal of Medicine, 367, 2375-2384. http://dx.doi.org/10.1056/NEJMoa1211585 
[19] Kim, Y.H., Park, D.W., Ahn, J.M., Yun, S.C., Song, H.G., Lee, J.Y., Kim, W.J., Kang, S.J., Lee, S.W., Lee, C.W., Park, S.W., Jang, Y., Jeong, M.H., Kim, H.S., Hur, S.H., Rha, S.W., Lim, D.S., Her, S.H., Seung, K.B., Seong, I.W., Park, S.J. and PRECOMBAT-2 Investigators (2012) Everolimus-Eluting Stent Implantation for Unprotected Left Main Coronary Artery Stenosis the PRECOMBAT-2 (Premier of Randomized Comparison of Bypass Surgery versus Angioplasty Using Sirolimus-Eluting Stent in Patients with Left Main Coronary Artery Disease) Study. Journal of the American College of Cardiology, 5, 708-717. http://dx.doi.org/10.1016/j.jcin.2012.05.002

[20] Boudriot, E., Thiele, H., Walther, T., Liebetrau, C., Boeckstegers, P., Pohl, T., Reichart, B., Mudra, H., Beier, F., Gansera, B., Neumann, F.J., Gick, M., Zietak, T., Desch, S., Schuler, G. and Mohr, F.W. (2011) Randomized Comparison of Percutaneous Coronary Intervention with Sirolimus-Eluting Stents versus Coronary Artery Bypass Grafting in Unprotected Left Main Stem Stenosis. Journal of the American College of Cardiology, 57, 538-545. http://dx.doi.org/10.1016/j.jacc.2010.09.038

[21] Malenka, D.J., Leavitt, B.J., Hearne, M.J., Robb, J.F., Baribeau, Y.R., Ryan, T.J., Helm, R.E., Kellett, M.A., Dauerman, H.L., Dacey, L.J., Silver, M.T., VerLee, P.N., Weldner, P.W., Hettleman, B.D., Olmstead, E.M., Piper, W.D., O’Connor, G.T. and Northern New England Cardiovascular Disease Study Group (2005) Comparing Long-Term Survival of Patients with Multivessel Coronary Disease after CABG or PCI Analysis of BARI-Like Patients in Northern New England. Circulation, 112, I-371-I-376.

[22] Hannan, E.L., Racz, M.J., Walford, G., Jones, R.H., Ryan, T.J., Bennett, E., Culliford, A.T., Wayne Isom, O., Gold, J.P. and Rose, E.A. (2005) Long-Term Outcomes of Coronary-Artery Bypass Grafting versus Stent Implantation. New England Journal of Medicine, 352, 2174-2183. http://dx.doi.org/10.1056/NEJMoa040316

[23] Bair, T.L., Muhlestein, J.B., May, H.T., Meredith, K.G., Horne, B.D., Pearson, R.R., Li, Q., Jensen, K.R., Anderson, J.L. and Lappe, D.L. (2007) Surgical Revascularization Is Associated with Improved Long-Term Outcomes Compared With Percutaneous Stenting in Most Subgroups of Patients with Multivessel Coronary Artery Disease: Results from the Intermountain Heart Registry. Circulation, 116, I-226-I-231.

[24] Shiomi, H., Morimoto, T., Hayano, M., Furukawa, Y., Nakagawa, Y., Tazaki, J., Imai, M., Yamaji, K., Tada, T., Natsuaki, M., Saijo, S., Funakoshi, S., Nagao, K., Hanazawa, K., Ehara, N., Kadota, K., Iwabuchi, M., Shizuta, S., Abe, M, Sakata, R., Okabayashi, H., Hanyu, M., Yamazaki, F., Shimamoto, M., Nishiwaki, N., Imoto, Y., Komiya, T., Horie, M., Fujiwara, H., Mitsudo, K., Nobuyoshi, M., Kita, T., Kimura, T. on Behalf of the CREDO-Kyoto PCI/CABG Registry Cohort-2 Investigators (2012) Comparison of Long-Term Outcome after Percutaneous Coronary Intervention versus Coronary Artery Bypass Grafting in Patients with Unprotected Left Main Coronary Artery Disease (from the CREDOKyoto PCI/CABG Registry Cohort-2). American Journal of Cardiology, 110, 924-932. http://dx.doi.org/10.1016/j.amjcard.2012.05.022

[25] Chieffo, A., Meliga, E., Latib, A., Park, S.J., Onuma, Y., Capranzano, P., Valgimigli, M., Jegere, S., Makkar, R.R., Palacios, I.F., Kim, Y.H., Buszman, P.E., Chakravarty, T., Sheiban, I., Mehran, R., Naber, C., Margey, R., Agnihotri, A., Marra, S., Capodanno, D., Leon, M.B., Moses, J.W., Fajadet, J., Lefevre, T., Morice, M.C., Erglis, A., Tamburino, C., Alfieri, O., Serruys, P.W. and Colombo, A. (2012) Drug-Eluting Stent for Left Main Coronary Artery Disease: The DELTA Registry: A Multicenter Registry Evaluating Percutaneous Coronary Intervention versus Coronary Artery Bypass Grafting for Left Main Treatment. JACC: Cardiovascular Interventions, 5, 718-727. http://dx.doi.org/10.1016/j.jcin.2012.03.022

[26] Buszman, P.E., Buszman, P.P., Kiesz, R.S., Bochenek, A., Trela, B., Konkolewska, M., Bradley, D.W., Wilczynski, M., Szkrobka, I.B., Przybyla, E.P., Krol, M., Kondys, M., Milewski, K., Wiernek, S., Debinski, M., Zurakowski, A.Z., Martin, J.L. and Tendera, M. (2009) Early and Long-Term Results of Unprotected Left Main Coronary Artery Stenting the LE MANS (Left Main Coronary Artery Stenting) Registry. Journal of the American College of Cardiology, 54, 1500-1511. http://dx.doi.org/10.1016/j.jacc.2009.07.007

[27] Benedetto, U., Melina, G., Angeloni, E., Refice, S., Roscitano, A., Fiorani, B., Di Nucci, G.D. and Sinatra, R. (2009) Coronary Artery Bypass Grafting versus Drug-Eluting Stents in Multivessel Coronary Disease. A Meta-Analysis on 24,268 Patients. European Journal of Cardio-Thoracic Surgery, 36, 611-615. http://dx.doi.org/10.1016/j.ejcts.2009.03.012

[28] Bravata, D.M., Gienger, A.L., McDonald, K.M., Sundaram, V., Perez, M.V., Varghese, R., Kapoor, J.R., Ardehali, R., Owens, D.K. and Hlatky, M.A. (2007) Systematic Review: The Comparative Effectiveness of Percutaneous Coronary Interventions and Coronary Artery Bypass Graft Surgery. Annals of Internal Medicine, 147, 703-716. http://dx.doi.org/10.7326/0003-4819-147-10-200711200-00185

[29] Hoffman, S.N., TenBrook, J.A., Wolf, M.P., Pauker, S.G., Salem, D.N. and Wong, J.B. (2003) A Meta-Analysis of Randomized Controlled Trials Comparing Coronary Artery Bypass Graft with Percutaneous Transluminal Coronary Angioplasty: One- to Eight-Year Outcomes. Journal of the American College of Cardiology, 41, 1293-1304. http://dx.doi.org/10.1016/S0735-1097(03)00157-8

[30] Hlatky, A.A., Boothroyd, D.B., Bravata, D.M., Boersma, E., Booth, J., Brooks, M.M., Carrié, D., Clayton, T.C., Danchin, N., Flather, M., Hamm, C.W., Hueb, W.A., Kähler, J., Kelsey, S.F., King, S.B., Kosinski, A.S., Lopes, N., McDonald, K.M., Rodriguez, A., Serruys, P., Sigwart, U., Stables, R.H., Owens, D.K. and Pocock, S.J. (2009) Coronary Artery 
Bypass Surgery Compared with Percutaneous Coronary Interventions for Multivessel Disease: A Collaborative Analysis of Individual Patient Data from Ten Randomized Trials. Lancet, 373, 1190-1197. http://dx.doi.org/10.1016/S0140-6736(09)60552-3

[31] Sipahi, I., Akay, M.H., Dagdelen, S., Blitz, A. and Alhan, C. (2013) Coronary Artery Bypass Grafting vs. Percutaneous Coronary Intervention and Long-term Mortality and Morbidity in Multivessel Disease Meta-Analysis of Randomized Clinical Trials of the Arterial Grafting and Stenting Era. JAMA Internal Medicine. Published online 2 December.

[32] Park, S.J. and Park, D.W. (2009) Percutaneous Coronary Intervention with Stent Implantation versus Coronary Artery Bypass Surgery for Treatment of Left Main Coronary Artery Disease: Is It Time to Change Guidelines? Circulation: Cardiovascular Interventions, 2, 59-68. http://dx.doi.org/10.1161/CIRCINTERVENTIONS.108.831701

[33] de Lezo, J.S., Medina, A., Pan, M., Delgado, A., Segura, J., Pavlovic, D., Melián, F., Romero, M., Burgos, L., Hernández, E., Ureña, I. and Herrador, J. (2004) Rapamycin-Eluting Stents for the Treatment of Unprotected Left Main Coronary, Disease. American Heart Journal, 148, 481-485. http://dx.doi.org/10.1016/j.ahj.2004.03.011

[34] Task Force on Myocardial Revascularization of the European Society of Cardiology (2010) Guidelines on Myocardial Revascularization. European Journal of Cardio-Thoracic Surgery, 38, S1-S52. http://dx.doi.org/10.1016/j.ejcts.2010.08.019

[35] Steigen, T.K., Maeng, M., Wiseth, R., Erglis, A., Kumsars, I., Narbute, I., et al. (2006) Randomized Study on Simple versus Complex Stenting of Coronary Artery Bifurcation Lesions: The Nordic Bifurcation Study. Circulation, 114, 1955-1961. http://dx.doi.org/10.1161/CIRCULATIONAHA.106.664920

[36] Al Suwaidi, J., Yeh, W., Cohen, H.A., Detre, K.M., Williams, D.O. and Holmes Jr., D.R. (2001) Immediate and OneYear Outcome in Patients with Coronary Bifurcation Lesions in the Modern Era (NHLBI Dynamic Registry). American Journal of Cardiology, 87, 1139-1144. http://dx.doi.org/10.1016/S0002-9149(01)01482-5

[37] Yan, B.P., Clark, D.J., Buxton, B., Ajani, A.E., Smith, J.A., Duffy, S.J., Shardey, G.C., Skillington, P.D., Farouque, O., Yii, M., Yap, C.H., Andrianopoulos, N., Brennan, A., Dinhi, D. and Reid, C.M. (2009) Clinical Characteristics and Early Mortality of Patients Undergoing Coronary Artery Bypass Grafting Compared to Percutaneous Coronary Intervention: Insights from the Australasian Society of Cardiac and Thoracic Surgeons (ASCTS) and the Melbourne Interventional Group (MIG) Registries. Heart, Lung and Circulation, 18, 184-190. http://dx.doi.org/10.1016/j.hlc.2008.10.005

[38] Jang, J.S., Choi, K.N., Jin, H.Y., Seo, J.S., Yang, T.H., Kim, D.K., Kim, D.S., Urm, S.H., Chun, J.H., Kang, S.J., Park, D.W., Lee, S.W., Kim, Y.H., Lee, C.W., Park, S.W. and Park, S.J. (2012) Meta-Analysis of Three Randomized Trials and Nine Observational Studies Comparing Drug-Eluting Stents Versus Coronary Artery Bypass Grafting for Unprotected Left Main Coronary Artery Disease. American Journal of Cardiology, 110, 1411-1418. http://dx.doi.org/10.1016/j.amjcard.2012.06.051

[39] Morice, M.C., Serruys, P.W., Kappetein, A.P., Feldman, T.E., Ståhle, E., Colombo, A., Mack, M.J., Holmes, D.R., Torracca, L., van Es, G.A., Leadley, K., Dawkins, K.D. and Mohr, F. (2010) Outcomes in Patients with de Novo Left Main Disease Treated with either Percutaneous Coronary Intervention Using Paclitaxel-Eluting Stents or Coronary Artery Bypass Graft Treatment in the Synergy between Percutaneous Coronary Intervention with TAXUS and Cardiac Surgery (SYNTAX) Trial. Circulation, 121, 2645-2653. http://dx.doi.org/10.1161/CIRCULATIONAHA.109.899211

[40] Park, S.J., Kim, Y.H., Park, D.W., Yun, S.C., Ahn, J.M., Song, H.G., Lee, J.Y., Kim, W.J., Kang, S.J., Lee, S.W., Lee, C.W., Park, S.W., Chung, C.H., Lee, J.W., Lim, D.S., Rha, S.W., Lee, S.G., Gwon, H.C., Kim, H.S., Chae, I.H., Jang, Y., Jeong, M.H., Tahk, S.J. and Seung, K.B. (2011) Randomized Trial of Stents versus Bypass Surgery for Left Main Coronary Artery Disease. New England Journal of Medicine, 364, 1718-1727. http://dx.doi.org/10.1056/NEJMoa1100452

[41] Jiang, W.B., Zhao, W., Huang, H., Li, C.L., Zhang, J.H., Wang, Y. and Fu, G.S. (2012) Meta-Analysis of Effectiveness of First-Generation Drug-Eluting Stents versus Coronary Artery Bypass Grafting for Unprotected Left Main Coronary Disease. American Journal of Cardiology, 110, 1764-1772. http://dx.doi.org/10.1016/j.amjcard.2012.08.011

[42] Capodanno, D., Stone, G.W., Morice, M.C., Bass, T.A. and Tamburino, C. (2011) Percutaneous Coronary Intervention versus Coronary Artery Bypass Graft Surgery in Left Main Coronary Artery Disease: A Meta-Analysis of Randomized Clinical Data. Journal of the American College of Cardiology, 58, 1426-1432. http://dx.doi.org/10.1016/j.jacc.2011.07.005

[43] De Luca, G., Schaffer, A., Verdoia, M. and Suryapranata, H. (2013) Meta-Analysis of 14 Trials Comparing Bypass Grafting vs Drug-Eluting Stents in Diabetic Patients with Multivessel Coronary Artery Disease. Nutrition, Metabolism and Cardiovascular Diseases, in Press. http://dx.doi.org/10.1016/j.numecd.2013.11.002

[44] Niles, N.W., McGrath, P.D., Malenka, D., Quinton, H., Wennberg, D., Shubrooks, S.J., Tryzelaar, J.F., Clough, R., Hearne, M.J., Hernandez Jr., F., Watkins, M.W., O’Connor, G.T. for the Northern New England Cardiovascular Disease Study Group (2001) Survival of Patients with Diabetes and Multivessel Coronary Artery Disease after Surgical or Percutaneous Coronary Revascularization: Results of a Large Regional Prospective Study. Journal of the American College of Cardiology, 37, 1008-1015. http://dx.doi.org/10.1016/S0735-1097(00)01205-5 
[45] Mercado, N., Wijns, W., Serruys, P.W., Sigwart, U., Flather, M.D., Stables, R.H., O’Neill, W.W., Rodriguez, A., Lemos, P.A., Hueb, W.A., Gersh, B.J., Jean Booth, D. and Boersma, E. (2005) One-Year Outcomes of Coronary Artery Bypass Graft Surgery versus Percutaneous Coronary Intervention with Multiple Stenting for Multisystem Disease: A Meta-Analysis of Individual Patient Data from Randomized Clinical Trials. Journal of Thoracic and Cardiovascular Surgery, 130, 512-519. http://dx.doi.org/10.1016/j.jtcvs.2004.12.049

[46] Brener, S.J., Lytle, B.W., Casserly, I.P., Schneider, J.P., Topol, E.J. and Lauer, M.S. (2004) Propensity Analysis of Long-Term Survival after Surgical or Percutaneous Revascularization in Patients with Multivessel Coronary Artery Disease and High-Risk Features. Circulation, 109, 2290-2295. http://dx.doi.org/10.1161/01.CIR.0000126826.58526.14

[47] The Task Force on Myocardial Revascularization of the European Society of Cardiology (ESC) and the European Association for Cardio-Thoracic Surgery (EACTS) (2010) Guidelines on Myocardial Revascularization. European Heart Journal, 31, 2501-2555. http://dx.doi.org/10.1093/eurheartj/ehq277

[48] Fleisher, L.A., Beckman, J.A., Brown, K.A., Calkins, H., Chaikof, E.L., Fleischmann, K.E., Freeman, W.K., Froehlich, J.B., Kasper, E.K., Kersten, J.R., Riegel, B. and Robb, J.F. (2009) ACCF/AHA Focused Update on Perioperative Beta Blockade Incorporated into the ACC/AHA 2007 Guidelines on Perioperative Cardiovascular Evaluation and Care for Noncardiac Surgery. Journal of the American College of Cardiology, 54, e13-e118. http://dx.doi.org/10.1016/j.jacc.2009.07.010

[49] Kushner, F.G., Hand, M., Smith Jr., S.C., et al. (2009) Focused Updates: ACC/AHA Guidelines for the Management of Patients with ST-Elevation Myocardial Infarction (Updating the 2004 Guideline and 2007 Focused Update) and ACC/AHA/SCAI Guidelines on Percutaneous Coronary Intervention (Updating the 2005 Guideline and 2007 Focused Update) a Report of the American College of Cardiology Foundation/ American Heart Association Task Force on Practice Guidelines. Journal of the American College of Cardiology, 54, 2205-2241. http://dx.doi.org/10.1016/j.jacc.2009.10.015

[50] Patel, M.R., Dehmer, G.J., Hirshfeld, J.W., Smith, P.K. and Spertus, J.A. (2009) ACCF/SCAI/STS/AATS/AHA/ASNC 2009 Appropriateness Criteria for Coronary Revascularization: A Report of the American College of Cardiology Foundation Appropriateness Criteria Task Force, Society for Cardiovascular Angiography and Interventions, Society of Thoracic Surgeons, American Association for Thoracic Surgery, American Heart Association, and the American Society of Nuclear Cardiology: Endorsed by the American Society of Echocardiography, the Heart Failure Society of America, and the Society of Cardiovascular Computed Tomography. Circulation, 119, 1330-1352. http://dx.doi.org/10.1161/CIRCULATIONAHA.108.191768

[51] Breeman, A., Hordijk-Trion, M., Lenzen, M, Hoeks, S., Ottervanger, J.P., Bertrand, M.E., Sechtem, U., Zaliunas, R., Legrand, V., de Boer, M.J., Stahle, E., Mercado, N., Wijns, W. and Boersma, E. (2006) Treatment Decisions in Stable Coronary Artery Disease: Insights from the Euro Heart Survey on Coronary Revascularization. Journal of Thoracic and Cardiovascular Surgery, 132, 1001-1009. http://dx.doi.org/10.1016/j.jtcvs.2006.05.051

[52] Hannan, E.L., Racz, M.J., Gold, J., Cozzens, K., Stamato, N.J., Powell, T., Hibberd, M. and Walford, G. (2010) Adherence of Catheterization Laboratory Cardiologists to American College of Cardiology/American Heart Association Guidelines for Percutaneous Coronary Interventions and Coronary Artery Bypass Graft Surgery: What Happens in Actual Practice? Circulation, 121, 267-275. http://dx.doi.org/10.1161/CIRCULATIONAHA.109.887539

[53] Kim, L.J., King III, S.B., Kent, K., Brooks, M.M., Kip, K.E., Abbott, J.D., Jacobs, A.K., Rihal, C., Hueb, W.A., Alderman, E., Pena Sing, I.R., Attubato, M.J. and Feit, F. (2009) Factors Related to the Selection of Surgical versus Percutaneous Revascularization in Diabetic Patients with Multivessel Coronary Artery Disease in the BARI 2D (Bypass Angioplasty Revascularization Investigation in Type 2 Diabetes) Trial. JACC: Cardiovascular Interventions, 2, 384-392. http://dx.doi.org/10.1016/j.jcin.2009.01.009 